\title{
Arquivo Miyasaka em perspectiva etnográfica: o fotógrafo, as fotos e o pesquisador
}

Resumo: Esse texto é fruto da pesquisa de mestrado realizada junto ao Arquivo Miyasaka, um arquivo fotográfico particular localizado na cidade de Ribeirão Preto, São Paulo. A pesquisa se constituiu de uma etnografia do arquivo, de seu espaço, sua lógica organizacional, além das fotografias e pessoas que se relacionam com a produção fotográfica de Miyasaka e sua trajetória de vida. Aqui procurei refletir sobre o papel que as fotografias tiveram como interlocutoras durante toda a experiência de pesquisa, e sua atuação na construção do conhecimento, através das relações estabelecidas durante a trajetória de pesquisa, com o arquivo, as fotos e os interlocutores. Dessa relação estabelecida, foi possível se relacionar com um dos principais assuntos capturados pela lente de Miyasaka: a cidade de Ribeirão Preto.

Palavras-chave: Antropologia Visual; Etnografia; Arquivo; Fotografia; Miyasaka;

\section{Miyasaka Archive in ethnographic perspective: the photographer, the photos and the researcher}

\begin{abstract}
The text is the result of a master's research carried out next to the Miyasaka Archive, a private photographic archive located in the city of Ribeirão Preto, São Paulo. The research consisted of an ethnography of the archive, its space and organizational logic, besides the photos and the people that relate to the photographic production of Miyasaka and his life trajectory. Here I tried to reflect on the role of the photographs as interlocutors throughout the research experience, and their performance in the construction of knowledge, through the relations established during the research trajectory, with the archive, the photos and the interlocutors. From this established relation, it was possible to relate to one of the main subjects captured by Miyasaka lens: the city of Ribeirão Preto.
\end{abstract}

Keywords: Visual Anthropology; Ethnography; Archive; Photography; Miyasaka; 


\title{
Arquivo Miyasaka em perspectiva etnográfica: o fotógrafo, as fotos e o pesquisador
}

\author{
Rafael Bezzon
}

\section{Apresentação}

Como gosta Susan Sontag, uma "[...] foto é apenas um fragmento, seu peso moral e emocional depende do lugar em que se insere. [...]" (Sontag, 2004, p.122), dessa forma falar de uma fotografia sem ter em vista seu contexto de produção, circulação, uso ou pesquisa a torna uma foto suspensa no tempo, o recorte de um momento experienciado pelo produtor da foto que é congelado e transformado em imagem. A fotografia para ser entendida em toda sua potência expressiva, precisa que o observador, seja ele quem for, conheça os contextos de circulação em que determinada foto está inserida, além do momento histórico, social, econômico e cultural de sua produção.

Howard Becker em seu texto "Sociologia Visual, fotografia documental e fotojornalismo" (2009), propõe que as fotografias produzidas por diferentes pessoas inseridas em contextos distintos são muito parecidas, dessa forma a foto produzida pelo fotógrafo documentarista não se distingue muito da realizada pelo pesquisador quando em uma situação de pesquisa e o mesmo se passa com o fotojornalista - os três exemplos mobilizados por Becker. O que as diferencia são os contextos de utilização das fotos, e assim as interpretações acerca dessa imagem, uma fotografia publicada em uma pesquisa antropológica, sociológica ou de Ciências Sociais se insere em um contexto acadêmico, refletida e analisada por um conjunto de teorias que orientam a leitura proposta pelo pesquisador. Assim, como bem lembra Howard Becker, "Como todos objetos culturais, as fotografias ganham sentido a partir de seu contexto. [...]” (2009, p.190). A mesma foto publicada em um jornal é entendida e refletida de maneira

\footnotetext{
1 Mestre em Ciências Sociais pela UNESP/FCLAr. Pesquisador do Núcleo de Antropologia da Imagem e Performance (NAIP/UNESP/CNPq). Professor de Filosofia e Sociologia para o Ensino Médio. Contato: rafaelbezzon@gmail.com.

CSOnline - Revista Eletrônica de Ciências Sociais, Juiz de Fora, n. 24 (2017) Dez., pp. 1-309.
} 
diferente por estar inserida em outro contexto, o mesmo se passa para as fotos de um fotógrafo documentarista.

As imagens de maneira geral sempre foram utilizadas como forma de produção do conhecimento, principalmente como evidência de alguma coisa ou acontecimento, como prova de um fato científico, prática comum nas áreas de biológicas e exatas. Por muito tempo, nas ciências humanas, uso de imagens foi relegado como forma de construção do conhecimento e o mesmo se passou com as imagens produzidas em diferentes contextos e guardadas nos arquivos. Por muito tempo, e para algumas disciplinas, de acordo com Becker (2009, p.189), utilizar fotografias, desenhos, pinturas e gravuras foi tido como não científico. Desde a década de 1980 houve um grande aumento no interesse das Ciências Sociais e principalmente da Antropologia em pesquisas que utilizam a fotografia e arquivos fotográficos como objetos de reflexão antropológica e analisados a partir de uma perspectiva etnográfica.

A antropóloga Fraya Frehse, reflete a respeito dessa "perspectiva antropológica" em pesquisas que tem como escopo de trabalho os arquivos e seus diferentes objetos, dentre eles as fotografias. Para Frehse, a "perspectiva antropológica" se configura como "[...] uma 'postura' perante o conhecimento, uma maneira de justamente posicionar-se perante o contexto de estudo durante e após o trabalho de campo, nas etapas de análise e interpretação dos dados." (2006, p.301). É essa postura de que fala a antropóloga que estabeleci como modelo para realizar minha pesquisa de mestrado, que se passa dentro de um arquivo fotográfico particular na cidade de Ribeirão Preto, São Paulo, e também com os objetos e pessoas vivendo nesse espaço.

O arquivo em questão foi produzido ao longo de cinquenta anos, período em que esteve ativo o fotógrafo Tony Miyasaka. Sua produção foi intensa, são aproximadamente quatorze mil imagens compondo o Arquivo Miyasaka, entre negativos, fotografias em papel e fotografias digitalizadas, realizadas nos diferentes contextos de atuação do fotógrafo. Devido à grande quantidade de imagens que compõem o arquivo e o pouco tempo para a realização da pesquisa, escolhi etnografar uma parte do arquivo. O Arquivo Miyasaka é composto por três grandes conjuntos de fotografias: “Jovem Miyasaka”, são fotografias produzidas durante as décadas de 1950 e 1960; "Fotos Aéreas", imagens realizadas pelo fotógrafo e também comercializadas por ele em suas lojas; "Fotos Artísticas", fotografias de temáticas variadas produzidas, sobretudo, entre os anos de 1990 e 2000. 
Foi com o corpus "Jovem Miyasaka" que convivi durante o período de imersão etnográfica junto ao Arquivo Miyasaka, é um conjunto composto por aproximadamente três mil imagens, dentre negativos, fotos em papel e digitalizadas, que estão parcialmente catalogadas e organizadas. Apenas um terço das fotos compondo esse conjunto estão identificadas em uma planilha de Excel, com informações básicas a respeito do estado conservação, quantidade, tamanho, uma breve legenda explicativa e o número de registro.

É no início do ano de 1950 que Miyasaka inicia sua relação de trabalho com fotos na cidade de Ribeirão Preto. Os anos de 1950 e 1960 do século XX, são considerados os "anos dourados" da cidade de Ribeirão Preto, principalmente pela efervescência cultural vivida na cidade com a chegada da Faculdade de Medicina da USP, a criação do Cine Foto Clube de Ribeirão Preto, a inauguração da Escola de Belas Artes do Bosque e da Escola de Artes Plásticas de Ribeirão Preto, além do estabelecimento do Centro Experimental de Cinema, responsáveis por movimentar, sobretudo, a atmosfera cultural, social, política e econômica da cidade. Além disso, foi o período que Miyasaka mais fotografou a cidade e suas transformações e também atuou como fotógrafo profissional para diversos órgão da mídia impressa atuantes na cidade e no estado de São Paulo. É nesse período também que se estabelece a chamada Escola Paulista de fotografia (Costa; Silva, 2004, p.34) inaugurada através da atuação e reflexão de alguns membros do Foto Cine Clube Bandeirante ${ }^{2}$, com sede na cidade de São Paulo, principalmente nos finais da década de 1940 se estendendo até a metade dos anos de 1960, propondo um olhar moderno para a produção fotográfica tendo seu foco, entre outras coisas, nas cidades, seus espaços e habitantes.

Miyasaka foi um importante fotógrafo na cidade de Ribeirão Preto, sua atuação foi múltipla tendo trabalhado em praticamente todas as etapas de produção da fotografia, iniciou sua trajetória retocando retratos fotográficos junto de seu irmão mais velho Kazuo. Após um período nessa função, não se mostrando muito talentoso com o pincel e a tinta, assumiu a função de fotógrafo retratista para o estúdio da família, o Foto Miyasaka, localizado na região central da cidade de Ribeirão Preto, em frente à Catedral Metropolitana de São Sebastião um dos marcos da cidade. A empresa da família foi inaugurada no ano de 1950, e já no ano de 1955 monopolizava os serviços fotográficos e fílmicos em Ribeirão Preto e na região, sobretudo a

\footnotetext{
2 O Foto Cine Clube Bandeirante - FCCB, é ativo até os dias de hoje. Mais informações: http://www.fotoclub.art.br/.

CSOnline - Revista Eletrônica de Ciências Sociais, Juiz de Fora, n. 24 (2017) Dez., pp. 1-309.
} 
área conhecida como Alta Mogiana ${ }^{3}$. Sua atuação profissional não se limitou aos trabalhos realizados dentro do estúdio, prestou serviços fotográficos para diferentes órgãos governamentais, registrando os eventos culturais, políticos e sociais vinculados à prefeitura da cidade e também para a perícia da polícia. Fotografou para os principais jornais da cidade de Ribeirão Preto, seus assuntos eram variados, de registros sociais à eventos esportivos quando fotografou os jogos dos principais clubes de futebol de Ribeirão Preto: Botafogo e Comercial. O Estúdio Miyasaka, foi responsável por inserir na cidade e na região o trabalho de reportagem social, que se disseminou durante a década de 1950, tendo seu apogeu nos anos de 1960.

O conjunto "Jovem Miyasaka" é composto por fotos tematizando os principais assuntos que transitavam frente à objetiva do fotógrafo ribeirão-pretano. Grande parte das fotografias, aproximadamente metade do conjunto, são retratos de estúdio de pessoas importantes na cidade: professores da Usp, políticos, grandes empresários e fazendeiros morando na cidade e na região. A outra parte das fotografias são tomadas da cidade de Ribeirão Preto, de suas ruas, prédios e praças capturados pela câmera de Miyasaka e compõem um projeto pessoal do fotógrafo de documentação da cidade, seus espaços e habitantes. Como lembrou sua viúva, D. Tereza - Ela e sua filha, Elza, são as principais interlocutoras da pesquisa -, Miyasaka tinha por hábito aos finais de semana andar pela cidade com sua câmera e fotografar suas ruas, prédios, e pessoas, principalmente na região central. São várias as fotos produzidas sobre os prédios e os espaços da cidade em diferentes momentos, registrando as etapas de construção dos edifícios e as transformações ocorridas na cidade, construção de ruas, pontes, escolas e etc.

\section{Fotografias e interlocutores}

Diz Michel Agier (2015, p.19), "Não existe etnólogo sem uma partida, sem sair de casa e ir olhar o mundo, que começa bem perto, além do círculo privado, da casa, dos sentimentos familiares, amorosos, fraternais. Tomar uma distância daquilo que compõe o seu 'eu' é o primeiro passo. [...]”. Sair de casa e se propor a olhar de uma forma diferente,

\footnotetext{
${ }^{3}$ A região da Alta Mogiana compreende o nordeste do estado de São Paulo, está localizada no traçado da linha férrea que interligava São Paulo - Campinas - Ribeirão Preto, com a expansão da linha férrea seu alcance chegou à Poços de Caldas, Minas Gerais. Foi construída pela Companhia Mogiana, que deu nome à região. CSOnline - Revista Eletrônica de Ciências Sociais, Juiz de Fora, n. 24 (2017) Dez., pp. 1-309.
} 
inquiridora, para as situações cotidianas já se torna uma pequena partida para uma experiência antropológica, assim se passa com os arquivos fotográficos e suas fotografias.

Com o desenvolvimento dos equipamentos fotográficos e dos materiais, principalmente no século XX, se estabelece as condições necessárias para que a profissão de fotógrafo se estabeleça. Os arquivos fotográficos produzidos por essas pessoas se mostram de grande interesse para as Ciências Sociais e a Antropologia, afinal como esclarece Elizabeth Edwards (1996, p.24), uma fotografia antropológica ou que interessa o cientista social "[...] é qualquer uma da qual um antropólogo possa retirar informações visuais e significativas.[...]”, e mesmo aquelas “[...] que não foram criadas com intenções antropológicas, ou secundadas especificamente por conhecimento etnográfico, podem, todavia, ser apropriadas com finalidades antropológicas. [...]”. As fotografias, produzidas pelo fotógrafo ribeirão-pretano e que constituem seu arquivo se apresentam, dessa forma, como um conjunto interessante para a realização da pesquisa.

Assim busquei inquirir, refletir e me relacionar com o Arquivo Miyasaka através de uma etnografia de seu espaço e suas imagens. Minha partida em busca do arquivo se passa de forma sutil, saindo de casa para olhar a cidade onde vivo, em busca dos espaços privilegiados de realização da pesquisa, os arquivos públicos e privados, emaranhados com as coisas que o conformam e as pessoas a eles conectadas. Não tive que atravessar grandes distancias em busca de meus interlocutores, os arquivos estão nas cidades em instituições públicas que guardam seus itens, e também nas residências, muitas vezes guardados em armários e gavetas. As relações estabelecidas e o diálogo travado com as pessoas que utilizam, trabalham e habitam nos espaços dos arquivos, sejam eles onde estiverem, são de grande importância para que as memórias e lembranças, as histórias e detalhes, emaranhados com esses artefatos e a vida das pessoas, possam ser acessados.

As relações estabelecidas têm, sobretudo, a imagem fotográfica como seu elo de conexão entre as diferentes encontradas durante a realização da pesquisa. Proponho, dessa forma, pensar a imagem não apenas dentro de seus limites físicos, como o quadrado ou o retângulo em que estão fixadas a imagem fotográfica, mas através das relações estabelecida com e por elas (as imagens) com o observador, e os efeitos e afetos produzidos a partir desse encontro. É assim que busquei refletir sobre o campo de realização da pesquisa: os arquivos, além das imagens e os interlocutores que orientam o fazer da pesquisa. 
Os usuários do arquivo não se limitam apenas à família, além deles há as pessoas que atuaram diretamente no processo de higienização e reorganização do arquivo após a morte de Miyasaka. Tania, Érika e Leila, amigas ${ }^{4}$, pesquisadoras e companheiras de trabalho de Elza, foram as responsáveis por esse primeiro reordenamento-higienização do arquivo. Sobretudo Tania que, além de ajudar a reorganizar o arquivo, foi aluna de Tony no curso ${ }^{5}$ de fotografia criado e ministrado pelo fotógrafo, além de ser historiadora e trabalhar com fotografias. Tania se apresenta como uma interlocutora privilegiada na construção da pesquisa, principalmente sobre a obra do fotógrafo e a constituição de seu acervo. Esse processo é importante para pensar os arquivos como artefatos culturais, afinal eles são resultado de tentativas de constituir e ordenar conhecimentos realizadas tanto pelo produtor do arquivo, como nas intervenções dos usuários e pessoas trabalhando em sua organização. (Cunha, 2004, p.291).

Durante uma pesquisa que se propõe realizar uma etnografia, os acontecimentos ocorridos em campo se dão ao acaso da vida das pessoas, passados seis meses de convívio semanal com o arquivo, as imagens e os interlocutores, uma de minhas principais interlocutoras, Elza, me chamou para uma conversa. Ela então me comunicou que a partir do segundo semestre de 2015 até o a metade de 2016 estaria morando na Itália, em Milão, devido a uma bolsa de pesquisa conseguida por estar cursando doutorado no Instituto de Arquitetura e Urbanismo de São Carlos - IAU USP, e sua mãe mudaria para São Paulo para morar durante esse período na casa de sua irmã, Cristiane.

Assim, combinamos que continuaria a frequentar o arquivo mesmo com a partida de minhas principais interlocutoras, para que continuasse a ter acesso ao arquivo Elza encomendou uma cópia das chaves e colocou sob minha responsabilidade. Dessa forma, após a partida de Elza e D. Tereza a experiência com o arquivo e suas imagens se modificou, agora era apenas eu - pesquisador -, as fotografias e o arquivo, a antiga morada do fotógrafo. Continuei, durante o período de ausência de minhas interlocutoras, com a postura de olhar sistematicamente para o maior número de imagens compondo o "Jovem Miyasaka".

\footnotetext{
${ }^{4}$ Todas elas têm suas trajetórias de vida relacionadas com espaços de arquivo e museus, o que as qualifica para a realização do trabalho junto ao arquivo Miyasaka. Érika foi a responsável pelo estabelecimento e montagem do Arquivo Público e Histórico de Ribeirão Preto - Casa da Memória; Leila é atual diretora do Museu da Cana Instituto Cultural Engenho Central; Tania trabalhou por muito tempo no Arquivo Público e Histórico de Ribeirão Preto - Casa da Memória e no Museu Histórico Municipal.

${ }^{5}$ Atualmente, é Aiko Tony, filho do fotógrafo, quem ministra o curso de fotografia criado por Miyasaka.

CSOnline - Revista Eletrônica de Ciências Sociais, Juiz de Fora, n. 24 (2017) Dez., pp. 1-309.
} 
Continuei a proposta de relação com o arquivo e suas imagens orientado pela perspectiva teórica de ordem fenomenológica na relação estabelecida com as fotografias, privilegiando a experiência e os afetos vividos junto às imagens (Edwards 2002, p.70; 2011, p.185; Barthes, 2011, p.30) ao invés de descrições pormenorizadas sobre seus conteúdos. A postura perante as imagens se assemelha com aquela de Roland Barthes (2011), e assim “[...] comprometer-se com uma força, o afeto; [...]" que algumas fotografias estabelecem com o observador, afinal, devido às circunstâncias da pesquisa, "[...] me interessava pela Fotografia por "sentimento"; eu queria aprofundá-la, não como uma questão, um tema, mas como uma ferida: vejo, sinto, portanto, olho e penso." (Barthes, 2011, p.31).

As fotografias se edificam, dessa forma, como as principais interlocutoras da pesquisa durante o período de ausência de Elza e D. Tereza. As fotos necessitam de seus contextos para serem entendidas em toda sua potência, seja ele o momento da produção como a posição ocupada pelas fotos no próprio arquivo. Só assim é possível refletir com quais fotografias se relacionam, além das histórias e memórias emaranhadas em torno dessas imagens e que são expressas no contato com os observadores.

\section{Fotos em perspectiva antropológica}

O primeiro contato com algo desconhecido sempre surpreende quem o experimenta, em um primeiro momento não sabia o que impulsionava Miyasaka a fotografar me proporcionando uma surpresa ainda maior ao observar suas fotografias. Os temas eram os mais variados e condiziam com sua múltipla atuação como fotógrafo durante as décadas de 1950 e 1960, de vistas da cidade, pelo chão ou aéreas, retratos de estúdio, eventos sociais, registros da cidade e suas transformações pulavam aos olhos quando segurava uma fotografia ou pela tela do computador ${ }^{6}$. Desse conjunto, algumas fotos se destacaram e capturaram minha atenção, provocando e me afetando de maneiras distintas, mas tiveram duas imagens que emanaram forças mais intensas na relação com as imagens. Uma pela expressão caricatural no rosto de um

\footnotetext{
${ }^{6}$ Parte do conjunto de fotografias que compõem o "Jovem Miyasaka" estão digitalizadas, sem compressão em formato .tiff.

CSOnline - Revista Eletrônica de Ciências Sociais, Juiz de Fora, n. 24 (2017) Dez., pp. 1-309.
} 
dos envolvidos, contrastando com os outros rostos que compõem a fotografia e a outra por ser uma fotografia inusitada de três garotos, com rostos cheios de força, durante seu banho.

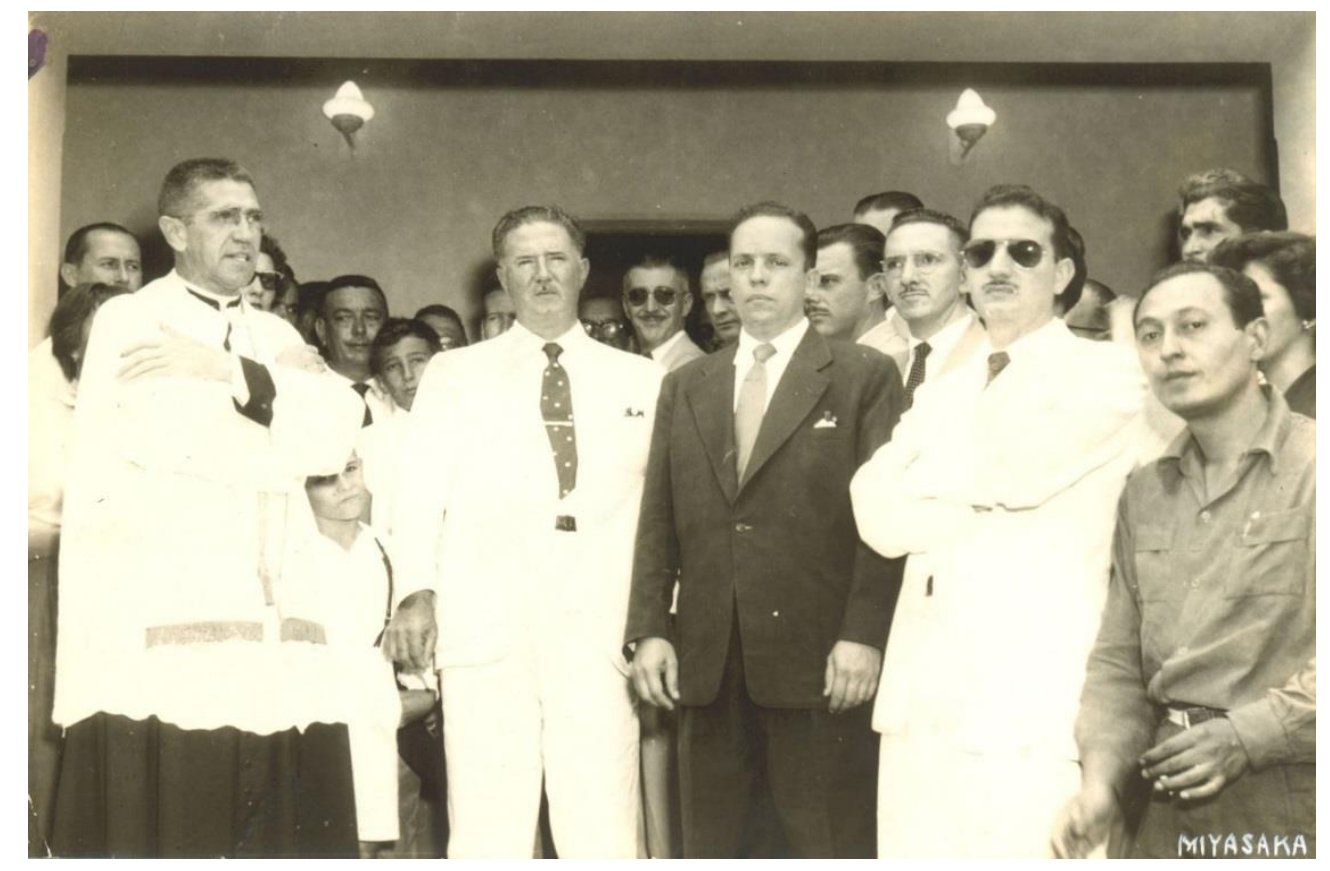

Imagem 1 - Cerimônia de inauguração de um prédio público. Autoria de Tony Miyasaka. Provavelmente entre os anos de 1952 e 1955.

As duas fotografias têm como traço marcante a presença do rosto como elemento provocador, pregnante, saltando da imagem. Elas, de certa forma, representam uma característica fundamental no trabalho de Miyasaka durante os anos de 1950 e 1960, sua atuação como foto repórter para jornais regionais e nacionais, além da realização de inúmeras reportagens sociais. A primeira, uma foto (Imagem 1) típica de eventos sociais e a segunda, (Imagem 2) um registro aparentemente encomendado de alunos, em uma situação pouco comum. Em seu arquivo particular as fotografias se misturam, não há uma definição clara de quais fotografias são de seu trabalho como foto repórter e quais não são.

As imagens se amalgamam, se misturam e se confundem, elas se apresentam como um grande enrosco de imagens, os trabalhos realizados como foto repórter se mesclam com os registros pessoais que fazia da cidade, fruto de um projeto pessoal do fotógrafo, por outro lado se emaranham com os inúmeros retratos fotográficos entrelaçados com as fotografias de arquitetura enlaçadas com as fotografias aéreas e outras de preocupação artística.

A primeira fotografia (Imagem 1) é um registro da inauguração de um órgão público, como consta no inventário do arquivo. Na foto há um grupo grande de pessoas esperando pelo CSOnline - Revista Eletrônica de Ciências Sociais, Juiz de Fora, n. 24 (2017) Dez., pp. 1-309. 
momento que o fotógrafo acionará sua câmera, em primeiro plano estão as autoridades responsáveis, um padre, um importante político do período: Ademar de Barros e o prefeito, à época, de Ribeirão Preto, Alfredo Condeixa Filho. A foto é típica das solenidades de inauguração de órgãos públicos, os olhares austeros, sérios, predominam dentro da foto. O que a torna provocante, despertando minha atenção, é um sorriso se destacando ante os rostos austeros, sorriso que é quase um rosto. Rosto-sorriso. É como se esse rosto trouxesse uma luminosidade diferente para uma foto-tipo tão comum.

O rosto-sorriso está localizado na intersecção dos corpos de Ademar de Barros e do prefeito da cidade, ele, intencionalmente ou não, está centralizado no interior do enquadramento da foto. É a única pessoa a sorrir no momento de tomada da foto, tornando a fotografia ainda mais inquietante. $\mathrm{O}$ rosto desse homem traz, para a fotografia, uma sensação de que há algo proibido durante o momento do seu riso, Riso-proibido. Como se o ato de sorrir estivesse fora de lugar, um sentimento de não pertencimento àquela ocasião e àquelas pessoas.

A segunda fotografia (Imagem 2) que provoca e afeta, as coisas se passam de outra maneira. Não é um grande evento, nem cerimônia, são três corpos seminus alinhados. É o fato da tomada ser um momento de intimidade dos garotos que a torna inquietante, provocadora, emanando uma força diferente dessa imagem. Cada corpo está emoldurado por um batente de madeira, há água escorrendo pelas matérias de músculo, sangue e pele, três corpos de jovens garotos. Os três rostos, como na outra foto (Imagem 1), também estão centralizados horizontalmente e divididos em três regiões, mas há um deles que parece reagir à câmera de Miyasaka. 


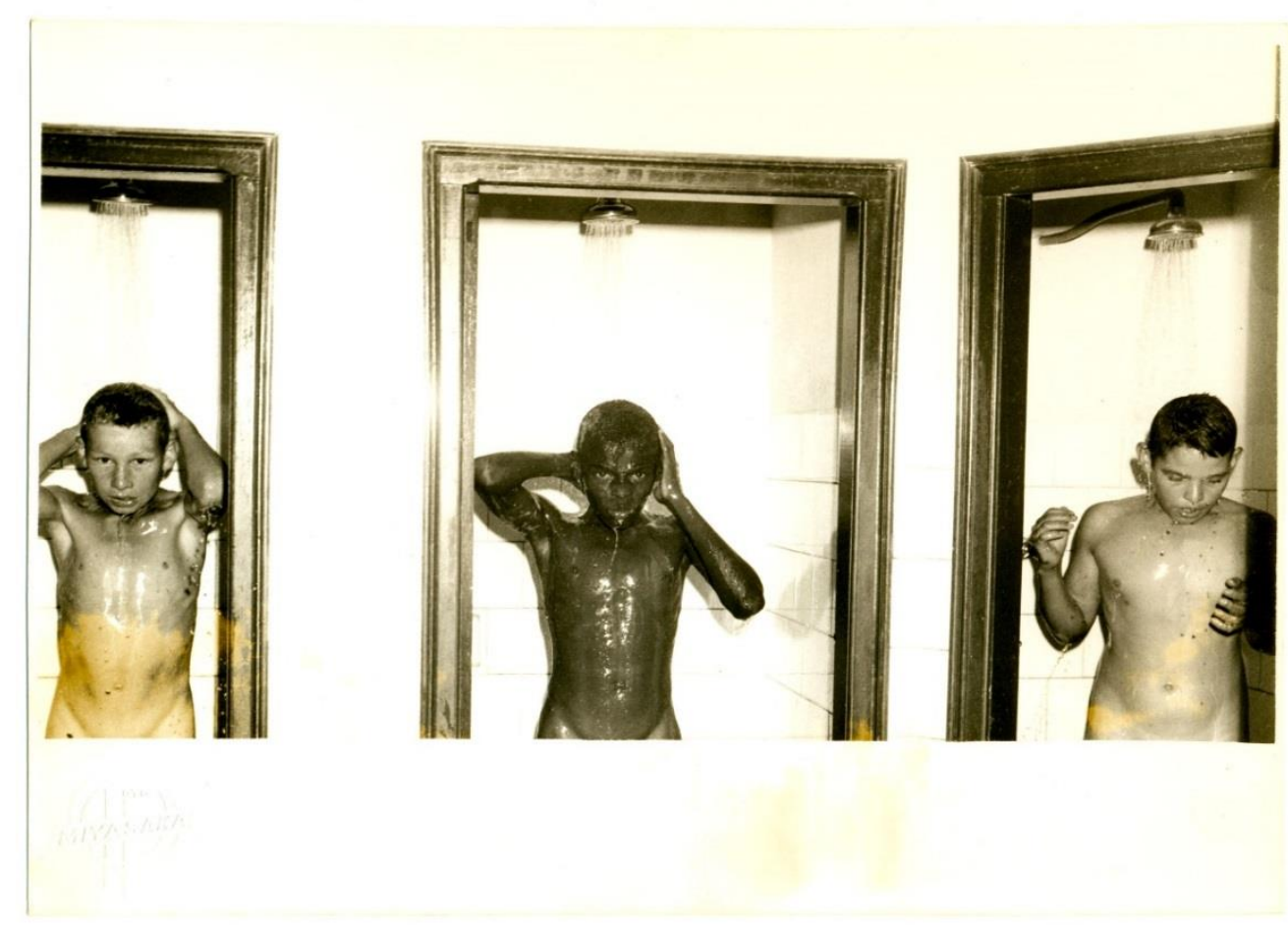

Imagem 2 - Garotos durante o banho, no Parque Infantil Peixe Abbade, conhecido como Parque Infantil do Barracão. Autor da fotografia Tony Miyasaka. Ano de 1961.

Como lembra Susan Sontag (2004, p.25) “[...] Fotografar pessoas é violá-las, ao vêlas como elas nunca se veem, ao ter delas um conhecimento que elas nunca podem ter; transforma pessoas em objetos que podem ser simbolicamente possuídos. [...]”, o rosto-reação é o localizado no centro do enquadramento da fotografia, é a essa violação de que fala Sontag que ele se torna reativo. $\mathrm{O}$ rosto do garoto encara a lente do fotógrafo, há nele uma expressão de agressividade, de contrariedade pela presença do fotógrafo durante o momento de seu banho e de realização da fotografia. É o único rosto a reagir, os outros dois garotos parecem não se importar com a presença da câmera, o da extremidade direita olha para baixo aparentemente absorto em pensamentos enquanto a água escorre sobre sua cabeça. $\mathrm{O}$ do extremo esquerdo da imagem, por outro lado, tem seu olhar perdido como se ele atravessasse a câmera e mirasse algo que estava atrás do fotógrafo, como se olhasse quem o olha.

\section{Olhando para o arquivo e vendo a cidade}


Meu primeiro encontro com a fotografia de Miyasaka se deu por intermédio desses rostos, seus detalhes, suas ações e reações em relação à câmera do fotógrafo. Esses rostos exerceram um grande efeito, como se tivessem me inebriado de suas presenças, e, indefeso frente a eles, me capturassem. A cidade de Ribeirão Preto e os acontecimentos que a envolvem também foram registrado pela câmera de Miyasaka.

O Arquivo Miyasaka se apresenta composto por diversas imagens que se emaranham entre elas, sejam elas fotografias analógicas e digitais, narrativas que envolvem a construção do arquivo, a história de vida do fotógrafo, as lembranças, memórias e histórias evocadas ao olhar e se relacionar com as fotografias também se configuram como imagens. Miriam Moreira Leite (1993), exemplifica bem essas relações entre fotografias, memórias e imagens, segundo a autora "[...] as fotografias poderiam ser comparadas a imagens armazenadas na memória, enquanto as imagens lembradas são resíduos substituíveis das experiências contínuas. Em muitos casos, lembranças das fotografias substituem lembranças de pessoas ou acontecimentos [...]" (p.145). O encontro com diferentes formas expressivas imagéticas, me despertou para um entendimento sobre o conceito de imagem como algo amplo, e não se apresentando apenas a partir dos suportes tradicionais como a escultura, o quadro, a fotografia e o cinema.

Dessa forma, a meu ver, se torna mais interessante pensar a fotografia a partir de uma reflexão que procure compreender sua potência de propiciar e facilitar relações entre as pessoas, mas, por outro lado, de estar entre as relações, mediando e criando elos entre diferentes forma expressivas. Como diz Elizabeth Edwards, pensar a imagem fotográfica em todo seu “[...] potencial para o alargamento teórico da fotografia que amplie ou até desestabilize o cânone teórico, e ao mesmo tempo a conecte com preocupações antropológicas fundamentais como memória, identidade, etnicidade, nacionalismo e globalização [...]" (2011, p.186-187). As fotografias se apresentam como artefatos imagéticos interessantes na evocação de memórias e como suportes que provocam a imaginação dos observadores, além de serem em si mesmos objetos relacionais.

A relação da fotografia com as Ciências Sociais ocorre desde a invenção das primeiras máquinas de captura de imagem, incorporadas pouco após sua invenção aos instrumentos de pesquisa e registro dos pesquisadores em campo. Em um primeiro momento, devido à sua característica de sempre ser imagem de alguma coisa, a partir de sua qualidade de espelhar o real (Leite, 1993, p.25-26), ela foi amplamente utilizada como prova. Por outro lado, a fotografia também foi utilizada como instrumento de evocação de histórias, lembranças e CSOnline - Revista Eletrônica de Ciências Sociais, Juiz de Fora, n. 24 (2017) Dez., pp. 1-309. 
memórias, prática conhecida como foto-elicitação e desenvolvida por diferentes pesquisadores, contudo esse uso da imagem fotográfica era entendido como uma via de mão única, ou seja, o pesquisador se utilizava do interlocutor para produzir informações. Conforme os paradigmas teórico-metodológicos das Ciências Sociais e, principalmente, da Antropologia foram sendo discutidos e reconfigurados, as práticas desenvolvidas nas pesquisas de campo também se transformaram.

A foto-elicitação, ou a prática de ver fotos em conjunto com o observador, também se reconfigurou como observa Elizabeth Edwards, “[...] A análise antropológica se volta, em vez disso, para o modo como as fotografias assumem sua própria dinâmica de sociabilidade junto às comunidades. [...]” (2011, p.180-181). Outra importante mudança ocorrida durante esse período, e que se relaciona com a transformação ante o entendimento das relações estabelecidas entre pesquisador, interlocutores e objetos, proporciona uma aproximação para pensar as fotografias a partir de uma perspectiva fenomenológica (Barthes, 2011), se atentando para os afetos estabelecidos entre o observador e as fotografias. Permitindo refletir sobre as relações mediadas por essas imagens, e as novas relações estabelecidas pelo pesquisador e os interlocutores, a partir das fotografias, com outras imagens sejam elas narrativas, lembranças e memórias evocadas e mesmo outras fotografias.

Um desses momentos vividos juntos de minhas principais interlocutoras, D. Tereza e Elza, se deu quando estava olhando o livro ${ }^{7}$ de fotografias organizado por elas sobre a obra fotográfica de Miyasaka. Em uma de minhas idas ao arquivo Elza me contou que a organização do livro foi pensada como um grande catálogo sobre a obra do fotógrafo, perpassando sua produção junto à cidade de Ribeirão Preto e suas principais personalidades retratadas, sobretudo, nas fotos retratos realizadas por Miyasaka. Por outro lado, o livro foi uma forma de tratamento do luto por parte de sua família e um instrumento para manter a memória sobre o fotógrafo e sua produção viva.

Quando folheava o livro-memória, me deparo com uma composição de duas fotografias que retratam um acidente ocorrido no centro da cidade, na esquina da rua General Osório com a avenida Jerônimo Gonçalves. A primeira foto (imagem 3), localizada na parte superior da página, enquadra o acidente a partir do ponto de vista de quem está na rua General

\footnotetext{
${ }^{7}$ O livro em questão se chama: "Ribeirão Preto pelo olhar de Tony Miyasaka", publicado no ano de 2006, dois anos após a morte do fotógrafo.

CSOnline - Revista Eletrônica de Ciências Sociais, Juiz de Fora, n. 24 (2017) Dez., pp. 1-309.
} 
Osório olhando os veículos envolvidos no acidente de frente. Um carro com o para-choque caído na rua de paralelepípedo e um ônibus colidido com um poste aparentemente de iluminação pública, aparentemente o o veículo de transporte coletivo fazia a linha para a faculdade de medicina, como é possível ver no letreiro informativo localizado em sua dianteira. A foto é uma vista panorâmica da situação, a calçada estava apinhada de curiosos, interessados tanto no acidente, ocorrido na região central da cidade, como na presença de Miyasaka que ao fotografar a colisão captura os rostos atentos dos transeuntes ante à sua presença.

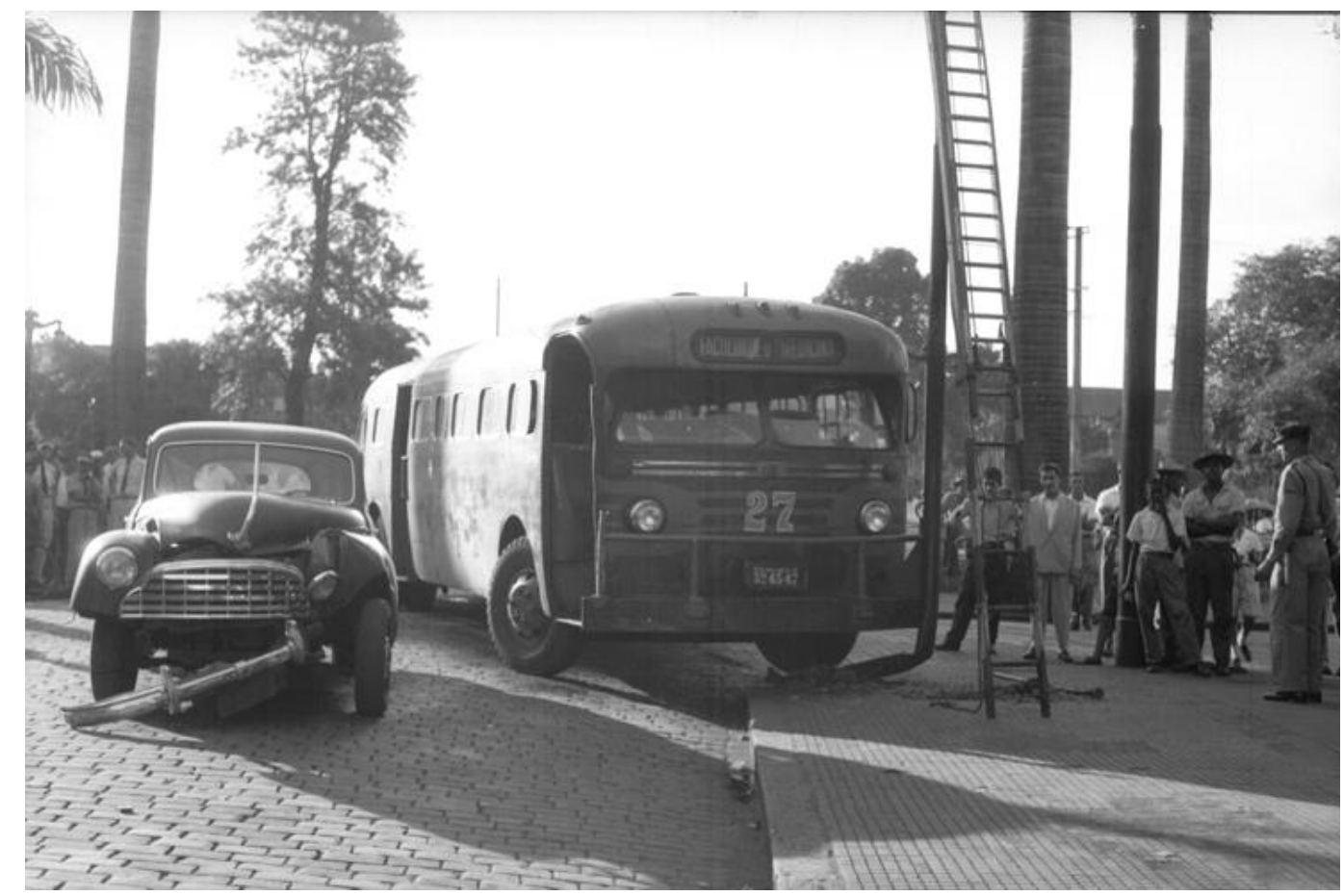

Imagem 3 - Fotografia de autoria de Tony Miyasaka, realizada no ano de 1960. Vista panorâmica do acidente ocorrida na esquina da rua General Osório com a avenida Jerônimo Gonçalves.

A segunda fotografia (imagem 4), localizada na parte de baixo da página, olha para o acidente a partir do ponto de vista de quem está na calçada da avenida Jerônimo Gonçalves. Miyasaka dessa vez enquadra o acidente pela lateral, ao lado esquerdo do fotógrafo há um trio de homens enfileirados aparentemente jovens, enquanto do lado direito, em oposição ao trio, um policial os observa. Ao fundo, em segundo plano, próximo à frente do carro está outro policial tomando o depoimento de uma das pessoas que observam a colisão. Há entre essas pessoas retratadas na imagem um aparente jogo de olhar. 


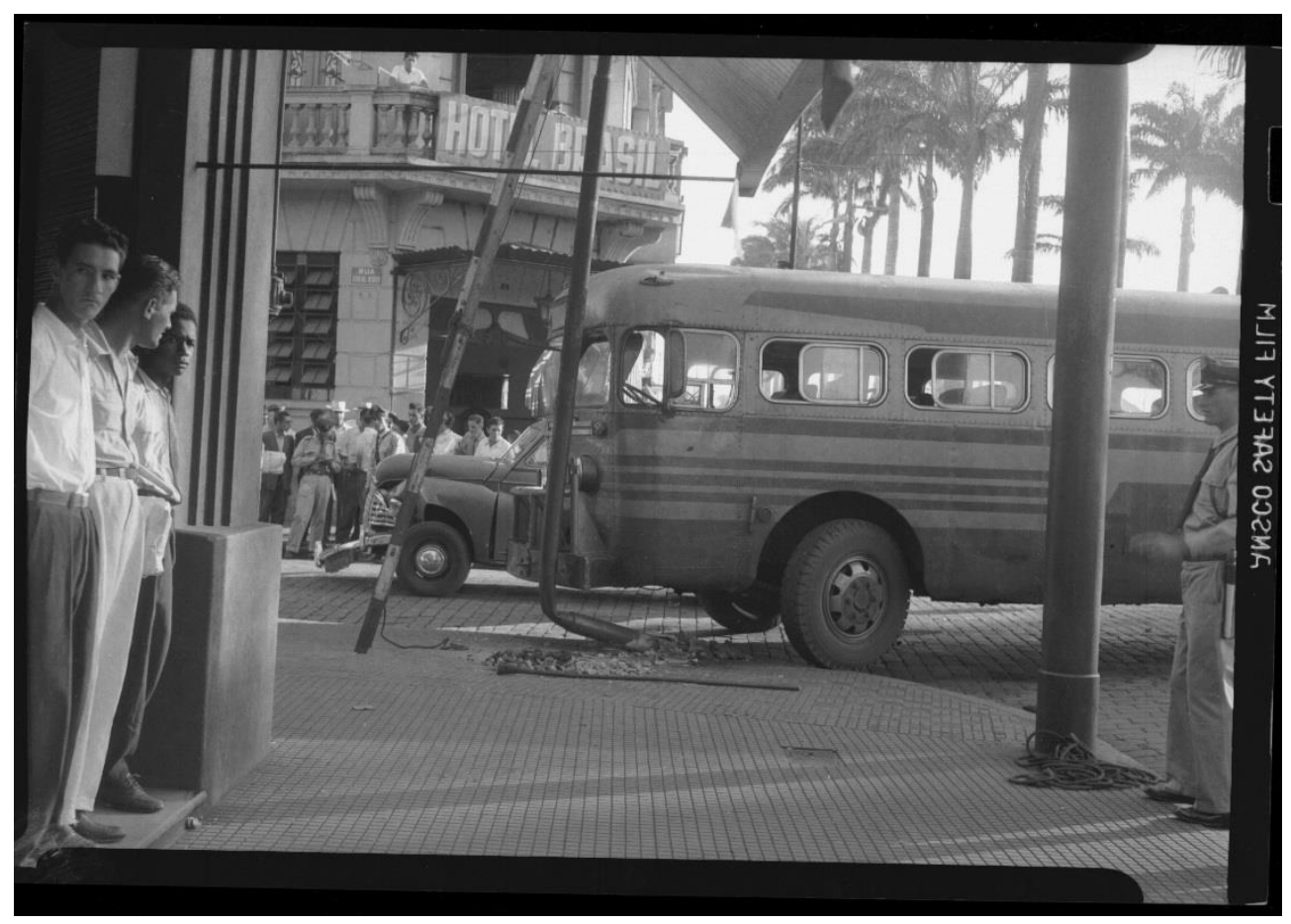

Imagem 4 - Fotografia de autoria de Tony Miyasaka, realizada no ano de 1960. Vista lateral do acidente ocorrido na esquina da rua General Osório com a avenida Jerônimo Gonçalves.

Os três rapazes à esquerda estão na porta de entrada de um estabelecimento comercial, o primeiro rapaz olha em direção ao fotógrafo, mas não para a câmera, parecia interessado em outra coisa que estava acontecendo no contra campo da imagem. O rapaz que está no meio olha em direção ao acidente, mas ao mesmo tempo parece olhar diretamente para o policial próximo à multidão em último plano, o terceiro rapaz, negro, olha diretamente, encara, a câmera de Miyasaka, seu rosto é iluminado por um feixe luz que o coloca em destaque. Do lado direito, o policial parece encarar os rapazes que estão parados observando a movimentação, por fim o policial ao fundo parece olhar em direção ao fotógrafo ou ao rapaz localizado ao meio. A imagem afeta e provoca meu olhar pela presença desse jogo de olhares realizados pelas pessoas compondo a fotografia, o fotógrafo também faz parte desse jogo, afinal sua presença e de sua câmera também se tornam parte desses olhares que se cruzam, se misturam e se envolvem.

As imagens três e quatro já estavam digitalizadas. Como parte do trabalho com as fotografias algumas foram selecionadas e impressas, dentre elas a imagem quatro. Em uma de minhas idas ao arquivo, levei a seleção de imagens impressas para que minhas interlocutoras, Elza e D. Tereza, olhassem essas fotografias junto comigo. Enquanto olhávamos as fotografias impressas, D. Tereza ao bater o olho na fotografia do acidente, separou ela do conjunto de imagens e pegou a fotografia para poder olhar com mais calma e atenção. Foi então que ela começou a contar, para mim e Elza, informações que a fotografia não nos fornecia, logo CSOnline - Revista Eletrônica de Ciências Sociais, Juiz de Fora, n. 24 (2017) Dez., pp. 1-309. 
lembrou que no dia do acidente Miyasaka estava trabalhando, à época ele prestava serviços fotográficos para os órgãos da polícia registrando as ocorrências, e o carro envolvido no acidente era do próprio fotógrafo.

Resolvi dar mais uma olhada no conjunto de fotografias digitalizadas para ver se encontrava outras fotos desse acidente, afinal como relembrou sua viúva, o próprio fotógrafo estava envolvido. Encontro uma pasta com quatro fotografias, as duas já citadas e outras duas abordando o acidente de outros ângulos. Em uma das fotos (imagem 5), Miyasaka enquadra a cena pegando a traseira dos dois veículos e olhando para a rua General Osório que segue em direção ao centro da cidade. Na imagem é possível ver a movimentação de pessoas que transitavam pelo centro da cidade, além de dois policiais, já vistos na imagem quatro, pegando o depoimento de um dos transeuntes que aparentemente viu o acidente e conta os fatos.

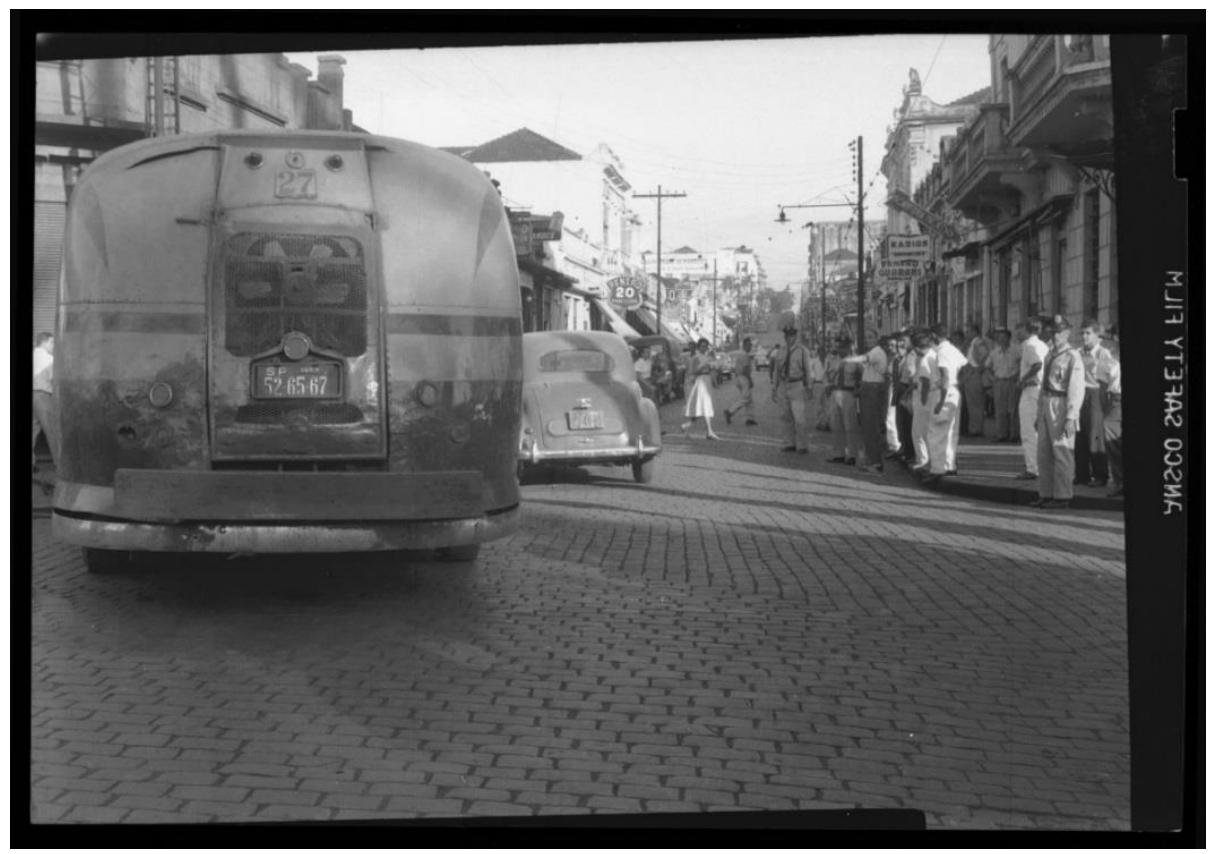

Imagem 5 - Fotografia de autoria de Tony Miyasaka, realizada no ano de 1960. Vista do acidente a partir da rua General Osório, que segue seu curso em direção ao centro da cidade. 


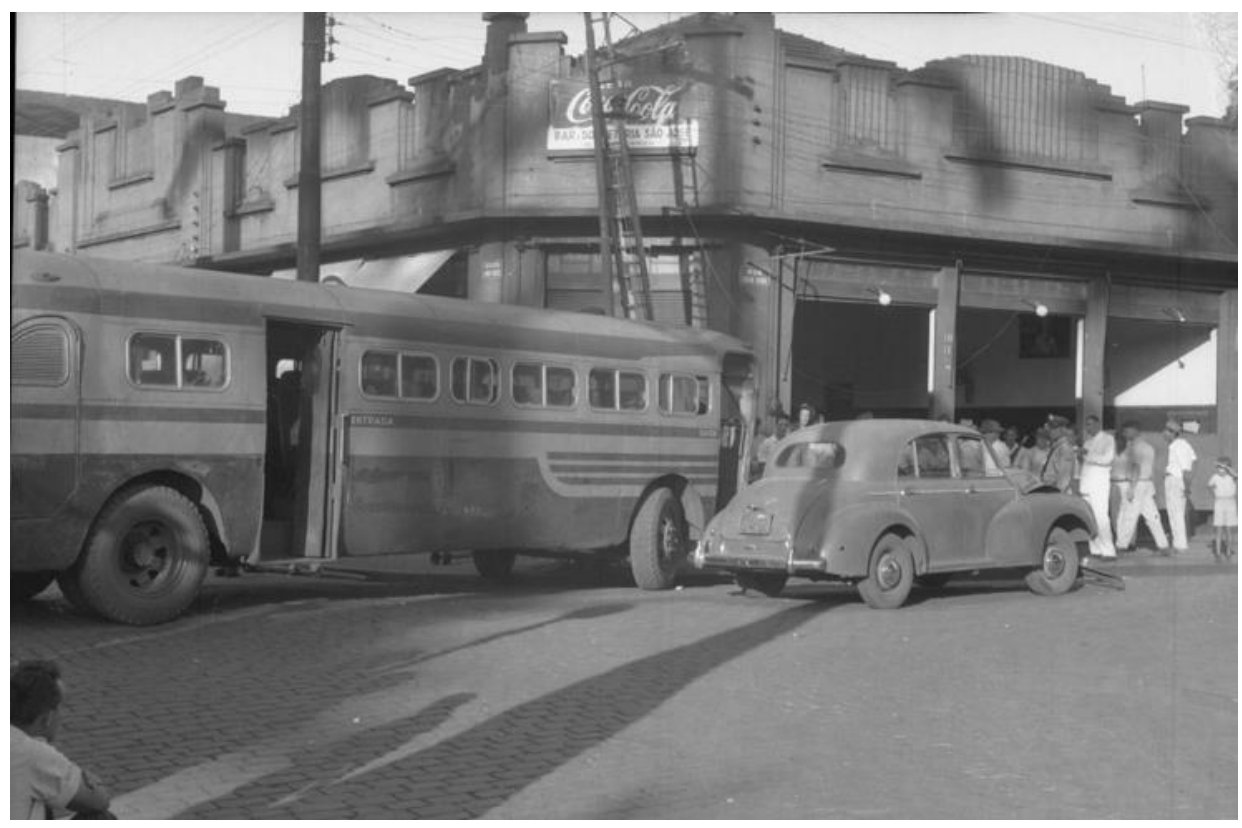

Imagem 6 - Fotografia de autoria de Tony Miyasaka, realizada no ano de 1960. Vista lateral do acidente, a partir da calçada da rua General Osório onde está o "Hotel Brasil".

A outra fotografia (imagem 6) enquadra a cena do ponto de vista de quem está na avenida Jerônimo Gonçalves na calçada do Hotel Brasil, a partir dessa imagem é possível ver o nome do estabelecimento comercial onde estão os três rapazes enfileirados da imagem quatro, "Bar e Sorveteria São José”. O envolvimento de Miyasaka no acidente, como lembra D. Tereza, pode ser o motivo dessa série de fotografias sobre o ocorrido. A análise individual das fotografias não permitiria o entendimento de todo o contexto de sua produção, as imagens publicadas no livro-memória eram partes dessa série produzida por Miyasaka, segundo Christopher Morton (2005, p.398) é importante entender as fotografias fora de seu contexto de publicação e investigar como elas se constituem no arquivo, sua organização e classificação permitindo compreender as relações entre as imagens que compõem a série, e as relações possíveis com outras fotografias.

\section{Fechando pensamentos}

A relação entre fotografia e antropologia, segundo Elizabeth Edwards (2015, p.236), pode ser caracterizada, por um lado, através de um embate entre evidência, pois a imagem está 
sempre relacionada com seu referente além de comprovar a presença do produtor da imagem junto ao referente, e, por outro lado, através do afeto, de afetar-se pelas relações construídas com seus interlocutores, sejam eles quem forem, na produção do conhecimento. O conceito de afeto mobilizado por Edwards se liga à uma série de experiências subjetivas estabelecidas tanto pelo observador como pelo pesquisador e o interlocutor, dessa forma através da produção fotográfica de Miyasaka - e de seu arquivo - o observador é levado a experienciar a cidade, sendo afetado pelas fotografias e assim estabelecendo uma relação com elas, com a cidade e com a memória sobre Ribeirão Preto emaranhada nessas relações.

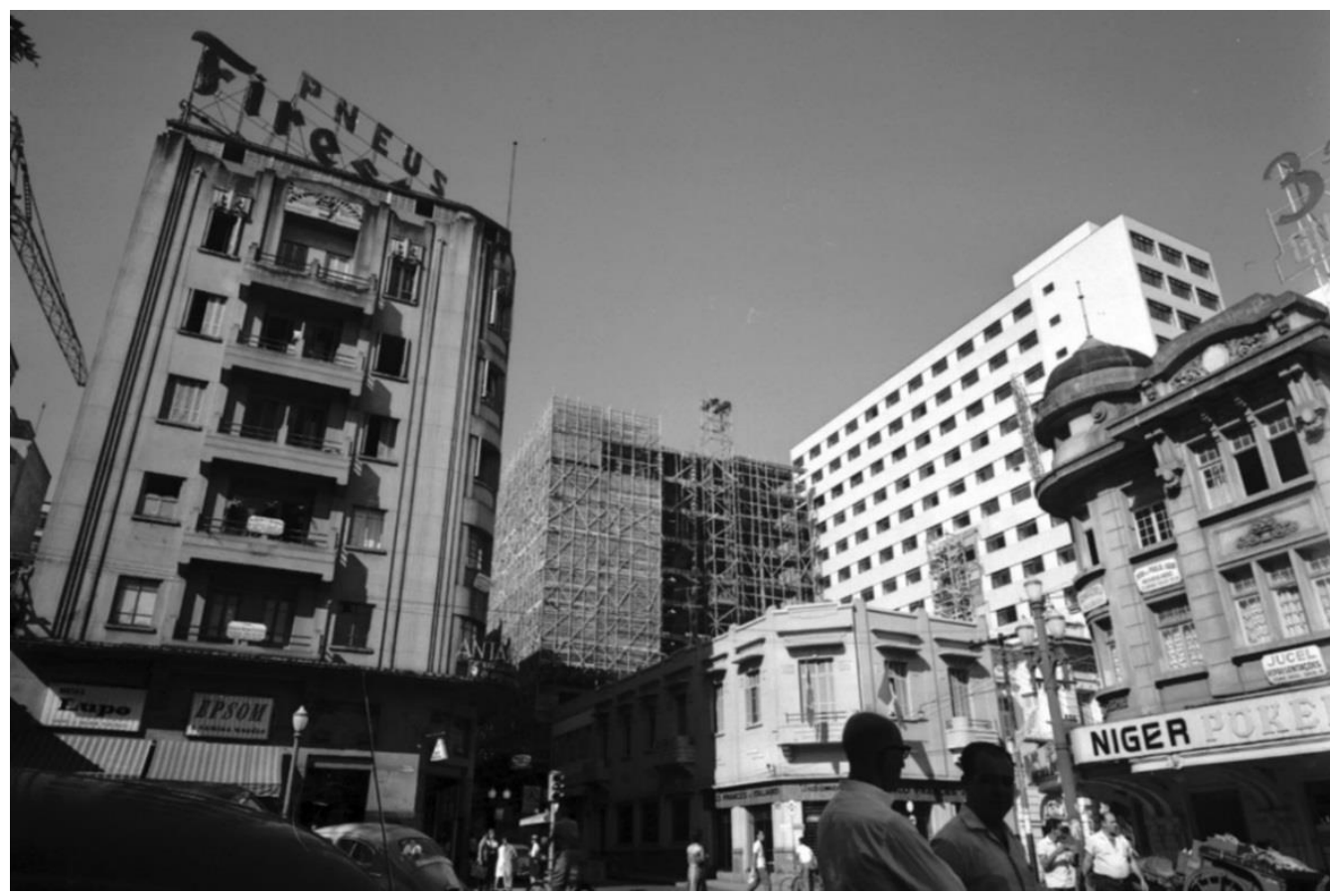

Imagem 7 - Fotografia de autoria de Tony Miyasaka. Realizada entre os anos de 1964 e 1968, devido a inexistência do Edifício Padre Euclides, que à época estava em construção. A região conhecida como "Quarteirão Paulista" compõe o centro histórico de Ribeirão Preto, se localiza no cruzamento das ruas: Álvares Cabral e General Osório.

Se relacionar com o Arquivo Miyasaka, seu espaço e lógica de organização, com as pessoas emaranhadas com as imagens, a trajetória do fotógrafo e o arquivo, e, sobretudo, com as fotografias permitem ao pesquisador olhar, também, para a cidade. É como se as fotografias de Miyasaka colocassem luzes sobre determinados acontecimentos, espaços e pessoas que estavam dormindo o sono arquivístico. As fotos e as séries, permitem ao observador e ao pesquisador se relacionarem com o arquivo e assim se relacionar com a cidade, mas aquela CSOnline - Revista Eletrônica de Ciências Sociais, Juiz de Fora, n. 24 (2017) Dez., pp. 1-309. 
construída através do olhar privilegiado do fotógrafo ribeirão-pretano durante as décadas de 1950 e 1960. O fotógrafo, ao olhar para a cidade, estabeleceu um projeto pessoal de documentação de seus espaços, acontecimentos e pessoas, é comum encontrar longas séries de fotografias retratando a construção de um prédio ou a reforma de uma rua, construção de uma ponte, ou seja, a cidade está sempre presente em suas fotografias assim como a experiência do fotógrafo na cidade, que é transformada em imagem com o auxílio da câmera.

\section{Referências bibliográficas}

AGIER, Michel. Encontros etnográficos: interação, contexto, comparação. 1. Edição, São Paulo: Editora Unesp; Alagoas: Edufal, 2015.

BARTHES, Roland. A câmara clara: nota sobre a fotografia. 3. Edição, Rio de Janeiro: Nova Fronteira, 2011.

BECKER, Howard. Sociologia visual, fotografia documental e fotojornalismo. In. BECKER, Howard. Falando da sociedade: ensaios sobre as diferentes maneiras de representar o social. 1. Edição, Rio de Janeiro: Jorge Zahar, 2009.

COSTA, Helouise \& SILVA, Renato Rodrigues da. A fotografia moderna no Brasil. 1. Edição, São Paulo: Cosac Naify, 2004.

CUNHA, Olívia Maria Gomes da. Tempo imperfeito: uma etnografia no arquivo. MANA, Rio de Janeiro, v.10, n.2, p.287-322 2004. Disponível em: http://www.scielo.br/pdf/mana/v10n2/25162.pdf [Consultado em 15 de Julho de 2017].

EDWARDS, Elizabeth. Antropologia e Fotografia. Cadernos de Antropologia e Imagem, Rio de Janeiro, v.2, p.11-28, 1996.

Material beings: objecthood and ethnographic photographs. Visual Studies, vol.17, n.1, p.67-75, 2002.

Photographs: Material Form and the Dynamic Archive. In. CARRAFA, Constanza. (org.). Photo archives and the photographic memory of art. 1. Edição, Berlin: DeutscherKunstverlag, 2011. 
FREHSE, Fraya. Potencialidades de uma etnografia das ruas do passado. Cadernos de Campo, São Paulo, n.14/15, p. 199-317, 2007.

MORTON, Cristopher. The Anthropologist as Photographer: Reading the Monograph and Reading the Archive. Visual Anthropology, v.18, p.389-405, 2005.

SONTAG, Susan. Sobre fotografia. 1. Edição, São Paulo: Companhia das Letras, 2004. 